\title{
Neutronics Requirements for a DEMO Fusion Power Plant
}

\author{
U. Fischera, C. Bachmann ${ }^{\text {b }}$, I. Palermoc, P. Pereslavtseva, R. Villarid \\ a) KIT, Karlsruhe, Germany, \\ b) EFDA, Garching, Germany, c)CIEMAT, Madrid, Spain \\ d) ENEA, Frascati, Italy
}

\section{Context}

- European Power Plant Physics and Technology (PPPT) programme

- Launched initially by EFDA, now conducted within the EUROfusion Consortium organisation.

- Conceptual design of DEMO power plant within "Horizon 2020" and the embedded roadmap to fusion.

- Key neutronics requirements must be fulfilled for DEMO to operate reliable and safe.

- Sufficient Tritium breeding and shielding performance to assured.

\section{Tritium breeding requirements}

- Tritium self-sufficiency must be guaranteed for DEMO: Net Tritium Breeding Ratio (TBR) $\geq 1.0$ mandatory

$\Rightarrow$ Global TBR with margin in excess of unity required to account for Tritium losses and uncertainties: TBR $\geq 1.0+\Delta$

\section{Uncertainties to be considered/to be accounted for:}

- Nuclear data uncertainties: 1-2 \% for liquid metal blankets utilizing $\mathrm{Pb}-\mathrm{Li}$, 5-10\% for solid breeder blankets with Beryllium

- Blanket mock-up experiments: Measured Tritium production perfectly reproduced for $\mathrm{HCLL}$, and underestimated by 5 to $10 \%$ for HCPB blanket mock-up.

$\Rightarrow$ No need for TBR margin related to nuclear data uncertainties

- Statistical uncertainties of Monte Carlo calculations: negligible

- Uncertainties due to modelling assumptions: depend on expert judgement and can be reduced to insignificant level $\leq 0.5 \%$

- Uncertainties due to specific engineering design assumptions: margin of 2 to $3 \%$ assumed; not mandatory - might be neglected if one can be sure the design is technically mature.

- Effect of ${ }^{6} \mathrm{Li}$ burn-up on TBR: negligible for Pb-Li based blankets; 1 to $2 \%$ TBR reduction for HCPB type blankets @ assumed DEMO blanket lifetime ( 2 to $5 \mathrm{fpy}$ ) and ${ }^{6} \mathrm{Li}$ enrichment (30 to 60\%).

- Effect of blanket ports on TBR: very important and significant, larger for Pb-Li than for HCPB type solid breeder/Be blankets.

\begin{tabular}{|l|c|c|}
\hline & Void ports & Plugged (steel) \\
\hline $\begin{array}{c}\text { Port surface area } \\
\text { \% of first wall area }\end{array}$ & $16 \times 1 \mathrm{~m} \times 2 \mathrm{~m}=32 \mathrm{~m}^{2}$ \\
$\begin{array}{c}\text { TBR reduction } \\
\text { HCPB DEMO }\end{array}$ & 2.95 \\
HCLL DEMO & $15 \%$ & $4 \%$ \\
\hline
\end{tabular}

- Tritium losses in fuel cycle: dominated by Tritium decay (5\%/year).

TBR design target: $\quad$ TBR $=1.10$ calculated by 3D Monte Carlo calculation not considering blanket ports and burn-up.

Rationale (pragmatic approach): Assume a conservative margin of $5 \%$ for Tritium losses in fuel cycle, neglect nuclear data uncertainties and burn-up, assign 5\% margin for port effect (limits the total port area to around $3 \%$ ).

\section{Objective}

- Specification of neutronic requirements for DEMO.

- Assessment of TBR uncertainties, specification of design margins and definition of TBR design target (mandatory).

- Radiation shielding requirements: tolerable radiation induced damage to vessel, limitation to the gas production in steel, and the radiation loads to the super-conducting magnets.

- Performance of current DEMO models based on HCPB ("helium cooled pebble bed", HCLL ("helium cooled lithium lead") and WCLL ("water cooled lithium lead") blanket concepts.

\section{Shielding requirements}

- Sufficient protection of the super-conducting magnets from radiation penetrating the blanket/vessel/shield system

$\Rightarrow$ Limits for the radiation loads on the Toroidal Field Coils (TFC) to prevent degradation of the superconductivity, the isolator function of the Epoxy resin, the mechanical strength of the (normal conducting) Cu stabilizer, and avoid excessive nuclear heating of the super-conductor that is to be removed.

\begin{tabular}{l|l}
\hline Total neutron fluence to epoxy insulator $\left[\mathrm{m}^{-2}\right]$ & $\begin{array}{l}1 \cdot 10^{22} \text { (equivalent to } \\
10^{7} \mathrm{Gray} \text { ) }\end{array}$ \\
\hline $\begin{array}{l}\text { Peak fast neutron fluence to the } \mathrm{Nb}_{3} \mathrm{Sn} \text { super- } \\
\text { conductor }\left[\mathrm{m}^{-2}\right]\end{array}$ & $1 \cdot 10^{22}$ \\
\hline $\begin{array}{l}\text { Peak displacement damage to Cu stabilizer } \\
\text { between TFC warm-ups }\left[\mathrm{m}^{-2}\right]\end{array}$ & $\begin{array}{l}1 \cdot 10^{21} \text { (equivalent to } \\
0.5 \cdot 10^{-4} \mathrm{dpa} \text { ) }\end{array}$ \\
\hline Peak nuclear heating in winding pack $\left[\mathrm{W} / \mathrm{m}^{3}\right]$ & $<0.05 \cdot 10^{3}$
\end{tabular}

$\Rightarrow$ Need to be proven for DEMO inboard mid-plane where minimum space is available for shielding.

$\Rightarrow$ Can be assured for HCPB, HCLL, WCLL DEMO with thickness of $70-75 \mathrm{~cm}$ for breeder modules (incl. manifold), $55 \mathrm{~cm}$ for vacuum vessel/shield utilizing WC or borated water.

- Irradiation induced displacement damage accumulation of the vessel to be limited to prevent degradation of the stainless steel properties.

$\Rightarrow 50$ dpa target limit for first wall $\rightarrow$ translates into blanket lifetime of $5 \mathrm{fpy}$.

$\Rightarrow 2.75 \mathrm{dpa}$ target limit for vacuum vessel made of austenitic stainless steel; results in plant lifetime of 5 and $10 \mathrm{fpy}$, for HCLL and HCPB DEMO, respectievly.

- Irradiation induced gas production accumulation to be limited to enable re-welding of components and connections/pipes made of steel.

$\Rightarrow$ Assumed limit for He gas concentration: 1 appm

$\Rightarrow$ DEMO design goal: In-vessel re-welding required only in dedicated areas where sufficient shielding can be provided (e. g. in vessel ports, or, at the bottom of blanket segments). 